\title{
Research on real time compensation of thermal errors of CNC lathe based on linear regression theory

\author{
Qiu Yongliang
}

\author{
Guangdong polytechnic of industry and commerce. Guangzhou 510510 \\ yongliang.qiu@163.com
}

Keywords: Precision machining; CNC lathe; Linear regression theory; Thermal error compensation

\begin{abstract}
In the field of precision machining, thermal error is one of the main error sources in CNC machining. The thermal error compensation of CNC lathe can effectively improve the machining accuracy of machine tools. On the basis of the research of local thermal error compensation technology in NC lathe, the temperature of the key points in CNC machining is real-time measured by platinum resistance temperature sensor. And the thermal error model is established by means of the fit of the measured temperature and linear regression theory. According to the thermal error model, the experiment of thermal error compensation is conducted, and the experimental results indicate that better surface quality is achieved with the implementation of the thermal error compensation.
\end{abstract}

\section{Introduction}

With the development of science and technology, the requirements for the accuracy of product are higher and higher. The methods of improving the machining accuracy of CNC lathe have mainly error avoidance method and error compensation method [1-2]. Error avoidance method which improves the machining accuracy of the lathe by improving the accuracy of parts of machine tools, using constant temperature workshop and so on will lead to an increase in the cost of workpiece. Error compensation method which is both economical and reliable has been a focal point of the research of CNC machining technology [3-4]. There are many factors which affect the machining accuracy of machine tools. And the thermal error which accounts for $40 \%-70 \%$ of the total machining error is one of the biggest error sources [5-6]. The influence of thermal error on the machining accuracy is more obvious for the $\mathrm{CNC}$ lathe of machining rotary parts because of the temperature of the workpiece is raising fast in the process of machining. The temperature of the motor, the rotary shaft, the feed shaft and the cutting tool and so on are measured by the platinum resistance temperature sensor. The thermal error model of CNC lathe is established based on linear regression theory. The temperature of the same measuring point is measured real-time in the CNC lathe machining, and real-time thermal error is calculated by thermal error model. Real-time compensation of thermal errors for $\mathrm{CNC}$ lathe is realized through thermal error compensation system.

\section{Placement of temperature sensor}

Both the friction heat between the moving parts and the environment temperature have some effects on the machining accuracy of the lathe. The machining point of the lathe can not be accurately positioned due to the thermal expansion of the lathe guide, thermal expansion of workpiece and so on. The machining error caused by the temperature change is called thermal error. The thermal error of the workpiece in lathe machining is mainly reflected in the machining accuracy of the $\mathrm{Z}$ axis, as shown in fig.1. 


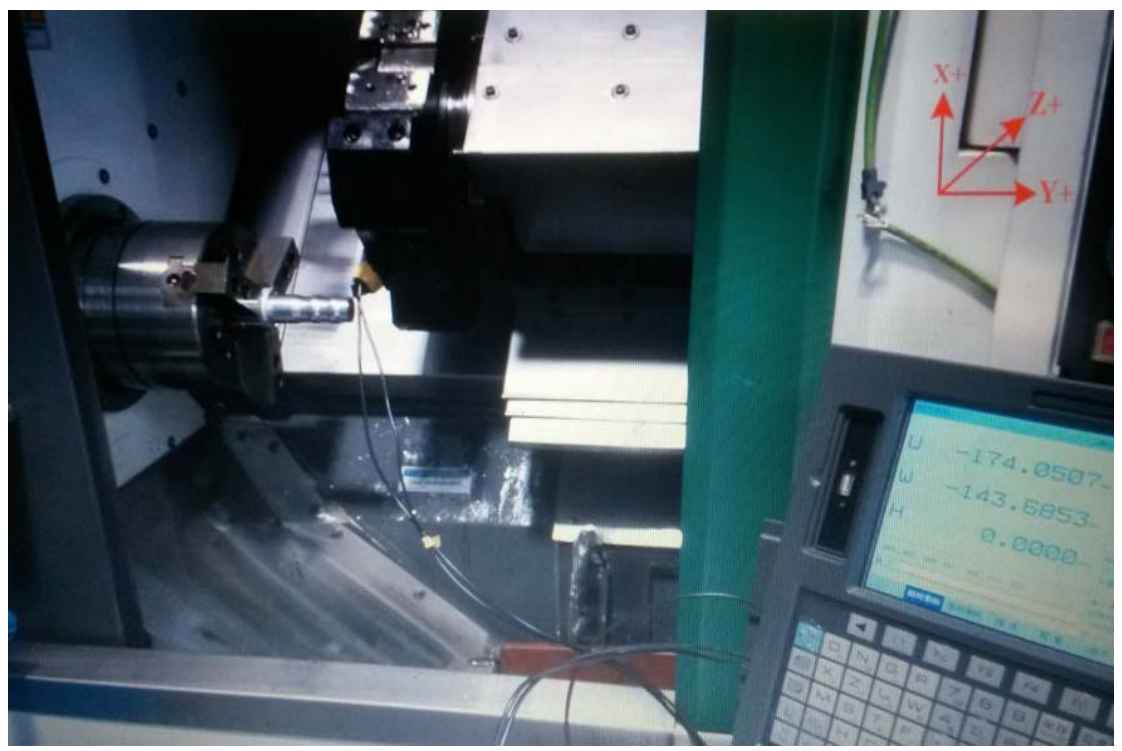

Fig.1 SJ320 oblique body CNC lathe

The placement of the temperature sensor is the key of the thermal error compensation effect. For CNC lathe machining, the main heat sources: heat of electric motor, friction heat between gears in the spindle box, cutting heat between the cutting tool and the workpiece, the friction heat between the guide rail and the ball screw, and so on. Therefore, the heat source affecting the accuracy of the workpiece is mainly concentrated in the spindle box, $\mathrm{X}$ axis guide, cutting tools, electric motor and so on. These heat sources are the key positions placing temperature sensor. The temperature sensor should be placed as close as possible to the heat source, and its number should be more than the number of heat source of the CNC lathe. If the conditions permit, the more temperature sensors are placed at the key point and the better the statistical effect.

\section{Thermal error model of CNC lathe}

The linear relationship between thermal error and temperature is established by using multiple linear regression theory, which is a common method of thermal error modeling ${ }^{[7-8]}$. The thermal error model established by this method has good reliability and high accuracy of prediction. According to the distribution of the heat source of the CNC lathe, $\mathrm{n}$ temperature measuring points are placed on the lathe. The temperature measured at each measuring point is recorded as: $T_{1}, T_{2}, \ldots, T_{n}$. Observe the change of the temperature, the $\mathrm{K}(\mathrm{k}=1,2, \ldots, \mathrm{m})$ group sample observation data were recorded as: $T_{1 k}, T_{2 k}, \ldots, T_{n k}$. At the same time, the machining error of the workpiece in the direction of the $\mathrm{Z}$ axis is recorded: $\Delta z_{1}, \Delta z_{2}, \ldots, \Delta z_{k}$. Linear equations can be obtained as follows:

$$
\left\{\begin{array}{c}
\Delta z_{1}=a_{0}+a_{1} T_{11}+\ldots+a_{n} T_{n 1}+\varepsilon_{1} \\
\Delta z_{2}=a_{0}+a_{1} T_{12}+\ldots+a_{n} T_{n 2}+\varepsilon_{2} \\
\Delta z_{3}=a_{0}+a_{1} T_{13}+\ldots+a_{n} T_{n 3}+\varepsilon_{3} \\
\quad \ldots . . \\
\Delta z_{k}=a_{0}+a_{1} T_{1 k}+\ldots+a_{n} T_{n k}+\varepsilon_{k}
\end{array}\right.
$$

The eq. (1) is changed into a matrix formula:

$$
\Delta Z=B A+\varepsilon
$$

Where, 


$$
A=\left(\begin{array}{l}
a_{0} \\
a_{1} \\
\ldots \\
a_{n}
\end{array}\right) ; B=\left(\begin{array}{ccccc}
1 & T_{11} & T_{21} & \ldots & T_{n 1} \\
1 & T_{12} & T_{22} & \ldots & T_{n 2} \\
\ldots & \ldots & \ldots & \ldots & \ldots \\
1 & T_{1 k} & T_{2 k} & \ldots & T_{n k}
\end{array}\right) ; \Delta Z=\left(\begin{array}{l}
\Delta z_{1} \\
\Delta z_{2} \\
\ldots \\
\Delta z_{k}
\end{array}\right) ; \varepsilon=\left(\begin{array}{l}
\varepsilon_{1} \\
\varepsilon_{2} \\
\ldots \\
\varepsilon_{k}
\end{array}\right)
$$

$a_{0}, a_{1}, \ldots, a_{n}$ are $\mathrm{n}+1$ parameters to be estimated. Both $T_{1 k}, T_{2 k}, \ldots, T_{n k}$ and $\Delta z_{1}, \Delta z_{2}, \ldots, \Delta z_{k}$ can be accurately measured. $\varepsilon_{0}, \varepsilon_{1}, \ldots, \varepsilon_{n}$ are independent random variables and obey normal distribution. Linear regression equation is established:

$$
y=a_{0}+a_{1} T_{1}+a_{2} T_{2}+\ldots+a_{n} T_{n}
$$

The square sum of the deviation is minimum to calculate the parameters $a_{0}, a_{1}, \ldots, a_{n}$, that is:

$$
M=\sum_{j=1}^{k}\left(y-y^{\prime}\right)^{2}=\min \sum_{j=1}^{k}\left(y_{j}-a_{0}-a_{1} T_{1 j}-a_{2} T_{2 j}-\ldots-a_{n} T_{n j}\right)^{2}
$$

Parameter $a_{0}, a_{1}, \ldots, a_{n}$ is the solution of the eq. (5) by the differential theory.

$$
\left\{\begin{array}{l}
\frac{\partial M}{\partial a_{0}}=-2 \sum_{j=1}^{n}\left(y_{j}-a_{0}-a_{1} T_{1 j}-\ldots-a_{n} T_{n j}\right)^{2} \\
\frac{\partial M}{\partial a_{1}}=-2 \sum_{j=1}^{n}\left(y_{j}-a_{0}-a_{1} T_{1 j}-\ldots-a_{n} T_{n j}\right)^{2} \\
\ldots \ldots \\
\frac{\partial M}{\partial a_{k}}=-2 \sum_{j=1}^{n}\left(y_{j}-a_{0}-a_{1} T_{1 j}-\ldots-a_{n} T_{n j}\right)^{2}
\end{array}\right.
$$

Therefore, the thermal error model is:

$$
\Delta z=a_{0}+a_{1} T_{1}+a_{2} T_{2}+\ldots+a_{n} T_{n}
$$

\section{Thermal error real-time compensation systems}

The thermal error real-time compensation system of CNC lathe which is composed of the software programming system, the real-time temperature measurement system and the servo system is a closed loop system, as shown in fig.2. The original CNC instruction of the CNC lathe needs to be determined according to the design of workpiece before the CNC machining. However, the original $\mathrm{CNC}$ instruction needs to be corrected according to the thermal error model and the feedback of the encoder because of thermal error. The temperatures of real-time measurement are substituted into the thermal model, and the thermal errors are calculated.

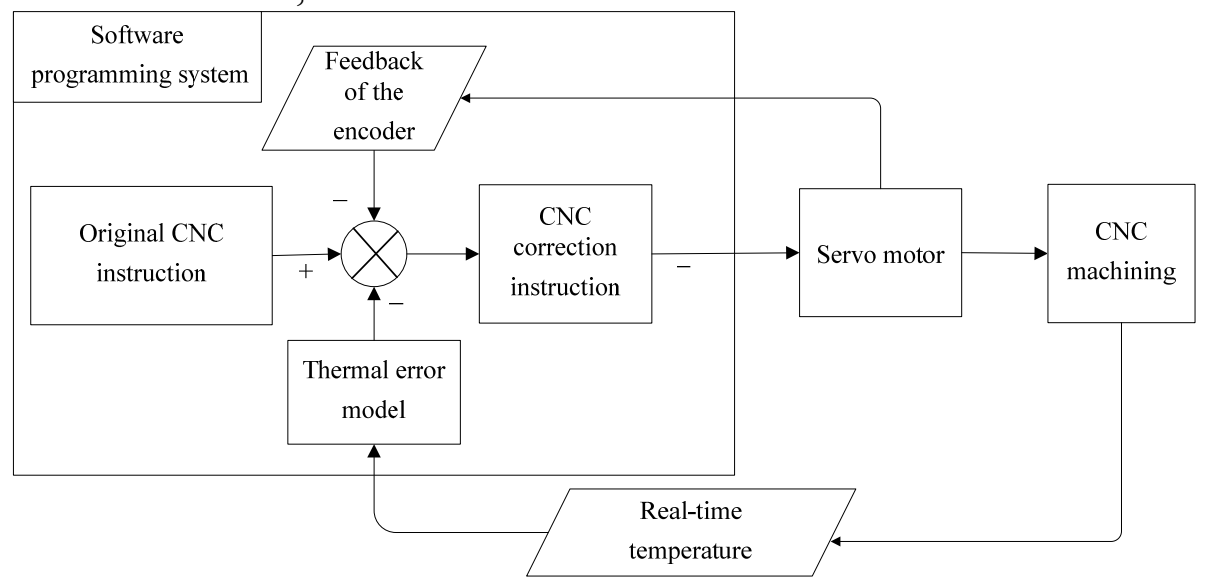

Fig.2. Thermal error real-time compensation systems 


\section{Implementation of thermal error compensation}

Based on key hot points of $\mathrm{CNC}$ lathe and principles for temperature sensor placement, four platinum resistance temperature sensors were installed in the spindle box, $\mathrm{X}$ axis guide rail, cutting tools and electric motor. In the machining of pure aluminum material, the temperature of the real-time measurement is recorded: $T_{1 k}, T_{2 k}, \ldots, T_{4 k}(\mathrm{k}=1,2, \ldots, 5)$. The machining errors of workpiece diameter relative each group temperature are measured with a vernier caliper. Five sets of machining errors are recorded as: $\Delta z_{1}, \Delta z_{2}, \ldots, \Delta z_{5}$.

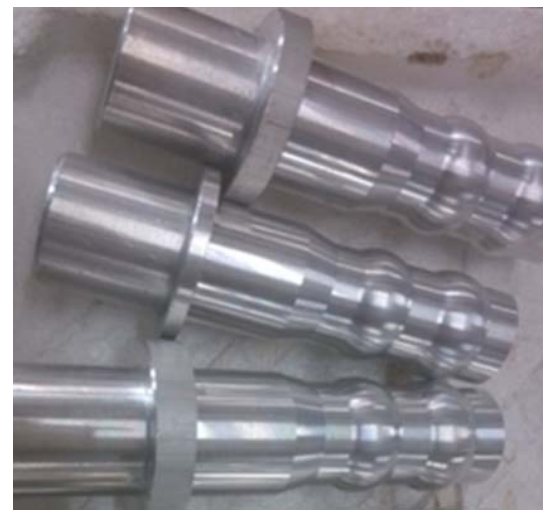

Fig.3 Workpieces of SJ320 oblique body CNC lathe

The temperature and the machining errors are substituted into the eq. (5), to calculate the parameters $a_{0}, a_{1}, \ldots, a_{5}$. Therefore, the thermal error model is described as:

$$
\Delta z=12.63-5.79 T_{1}-6.93 T_{2}+3.96 T_{3}+9.3 T_{4}
$$

The effect of thermal error compensation is shown in Figure 4. The results show that the effect of thermal error compensation of CNC lathe is obvious.

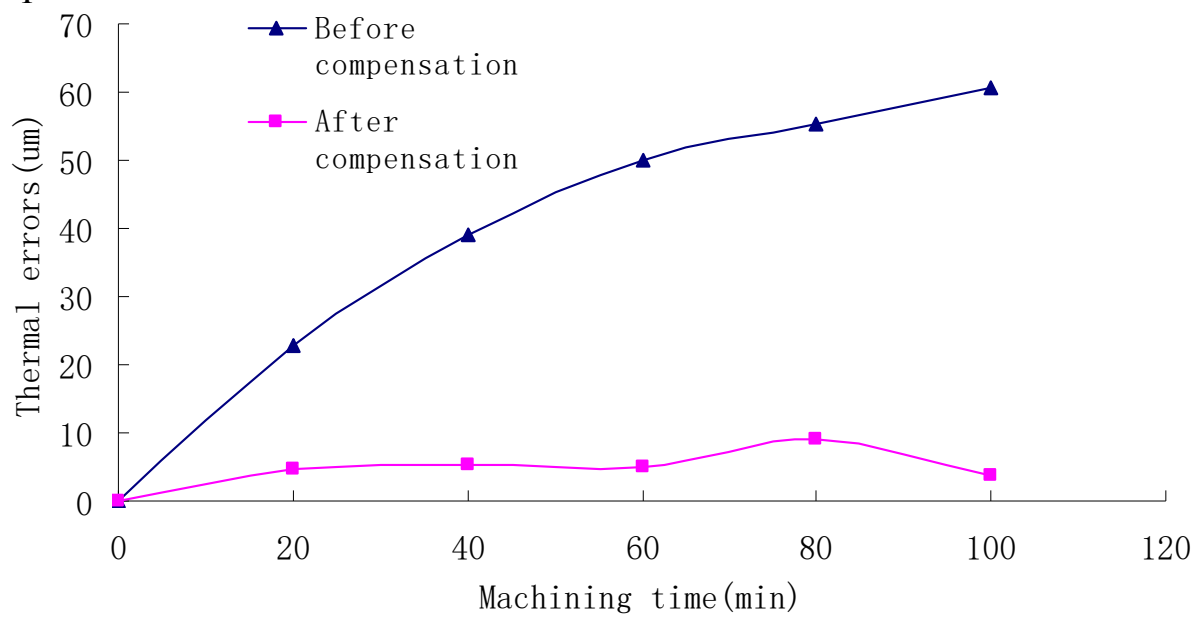

Fig.4 Effect of thermal error compensation

\section{Conclusions}

The thermal error compensation can effectively improve the machining accuracy of the CNC lathe. In this paper, the structure of numerical control lathe, heat source distribution and the influence of thermal error on the accuracy of the workpiece and so on are analyzed in detail. The heat source of the $\mathrm{CNC}$ lathe is found, which provides the basis for the placement of the temperature sensor. The thermal error model of $\mathrm{CNC}$ lathe is established based on linear regression theory and the temperature measured by multiple temperature sensors. The thermal error real-time compensation system based on thermal error model is developed. It is found by experiments that the placement of temperature sensor, thermal error model and thermal error compensation system are all reliable. 


\section{References}

[1] Lv Fengyu, He Chengzhu, Gou Weidong. Thermal error compensation system development of vertical machining center. Modular machine tool \& automatic manufacturing technique, 2014,6:80-85.

[2] Zhang Ting, Liu Shihao. Overview of thermal error compensation modeling for numerical control machine. Machine tool \& hydraulics, 2011,39(1):122-127.

[3] Guo Qianjian, Yang Jianguo, Wang Xiushan, et al. On-line measurement and compensation machining of thermal error for NC machine Tool. Manufacturing technology \& machine tool, 2007,4:32-37.

[4] Guo Qianjian,Yang Jianguo,Li Yongxiang, et al. Research on thermal error compensation technique of gear hobbing machine. China mechanical engineering,2007,23(18):2818-2821.

[5] Ma shuwen, Xu Zhongxing, Liu Lixin, et al. A study on thermal Error Compensation for the spindle of XH718 machining center. Mechanical science and technology, 2007,26(4):511-514.

[6] Gong Lingyun, Chen zeyu. Thermal error modeling and compensation of numericaI control machine tools, Manufacturing automation, 2012,34(1):42-69.

[7] Ji Changzhu. The research of CNC thermal error compensation system. Master degree dissertation, Hefei University of Technology, 2014.3.

[8] Wang Shilong, Yang Yong, Zhou Jie, et al. Modeling of thermal error compensation of large-scale numerical control gear hobbing machine. Journal of central south university, 2011,42(10):3066-3072. 